\title{
Trust matters: Why augmenting water supplies via desalination may not overcome perceptual water scarcity
}

\section{Authors: Maria Christina Fragkou and Jamie McEvoy}

NOTICE: this is the author's version of a work that was accepted for publication in Desalination. Changes resulting from the publishing process, such as peer review, editing, corrections, structural formatting, and other quality control mechanisms may not be reflected in this document. Changes may have been made to this work since it was submitted for publication. A definitive version was subsequently published in Desalination, [VOL\# 397, (November 2016)] DOI\# 10.1016/j.desal.2016.06.007

Fragkou , Maria Christina, and Jamie McEvoy. "Trust matters: Why augmenting water supplies via desalination may not overcome perceptual water scarcity." Desalination 397 (November 2016): 1-8. DOI: https://dx.doi.org/10.1016/i.desal.2016.06.007. 


\title{
Trust matters: Why augmenting water supplies via desalination may not overcome perceptual water scarcity
}

\author{
Maria Christina Fragkou ${ }^{\text {a, } *}$, Jamie McEvoy ${ }^{\text {b }}$ \\ a Department of Geography, Faculty of Architecture and Urbanism, Universidad de Chile, Portugal 84, Santiago, Chile \\ ${ }^{\mathrm{b}}$ Department of Earth Sciences, Montana State University, 226 Traphagen Hall, Bozeman, MT, USA
}

A B S T R A C T

\begin{abstract}
Historically, water scarcity has been understood to result from unfavorable climatological and hydrological factors. From this perspective, infrastructural solutions that augment water supplies, such as desalination, are seen as the way to overcome physical resource limits and resolve water scarcity. Drawing on theories of scarcity, risk perception, trust, and governance, we argue that past experiences with poor water quality and a long-standing mistrust of water providers create a particular mode of water scarcity: perceptual scarcity. This paper presents findings from household surveys conducted in two arid Latin American cities where large-scale desalination projects have been undertaken to provide potable water. While both projects use state-of-the-art desalination technology, our survey results indicate that the majority of respondents do not drink desalinated water from their taps and purchase bottled water instead. Our results show that, despite significant investments in infrastructure, respondents still lack an adequate supply of water that is perceived to be fit for human consumption. The two case studies provide empirical evidence that challenges the assumption that desalination technology will resolve water quality and water scarcity concerns. We conclude that institutional investments that promote a more reliable and trustworthy water governance system are as important as investments in physical infrastructure.
\end{abstract}

\section{Introduction}

Desalination - the process of converting saline water into freshwater through the removal of dissolved minerals - is increasingly viewed as a panacea to water scarcity. Under predictions of global decrease of available renewable water resources per capita $[37,68]$, the capacity to produce desalinated water has grown rapidly in the last decade, principally in coastal arid areas. For the period between 2008 and 2013 , the installed capacity has increased annually by a rate of $57 \%$, resulting in the installed capacity of 80 million $\mathrm{m}^{3}$ /day for 2013, provided by 17.000 plants, serving over 300 million people [33]. Due to improvements in membrane technology and energy recovery systems, the costs of desalination have been reduced by $50 \%$ in the last decade, making it a more attractive alternative [46]. This technology promises to overcome problems of low water availability and poor water quality in arid and semiarid regions where latent and existing conflicts over water allocation exist [60]. Desalinated water is promoted not only as an additional source of freshwater, but as a quality-controlled, premium form of "produced water" that is free of contaminants. Additionally, it can be viewed as a "green" technology where the use of desalinated water has the potential to reduce pressure on freshwater resources and allow more water for ecological flows $[11,39]$. In Spain, for example, desalination was promoted as a "...local, democratic, market efficient and ecologically sustainable" solution, when compared to the controversial solutions to scarcity such as inter-basin water transfers and 
river diversions [34]. On a more conceptual level, seawater is also free of the complex property rights and social, cultural and ecological meanings that are associated terrestrial waters and can lead to geopolitical conflicts [60].

Nevertheless, our results reveal that in two Latin American case studies, desalinated water does not meet consumers' most basic need. ${ }^{1}$ Our survey results show that consumers of desalinated water do not use it for drinking. Instead, survey respondents purchase bottled water to meet their households' drinking water needs. We argue that this preference for bottled water stems from previous experiences with poor water quality and a long-standing mistrust of water providers and government services.

In this paper, we apply theoretical concepts and survey methods from the social sciences to research on desalination - a field which, todate, has focused primarily on the technical aspects of this technology. In doing so, we provide empirical evidence which challenges the assumption that a state-of-the-art technical solution to water provision will address water quality (and water scarcity) concerns. These findings contribute new insights to the ongoing discussion of different ways of conceptualizing water scarcity by examining the role of risk perception and the production of perceptual scarcity. It also adds a new dimension to the growing body of literature on bottled water consumption by providing empirical results from household surveys on preferences for tap water versus desalinated water. These findings suggest that there is a need for more robust assessments of solutions to water scarcity that include investments in not only infrastructure, but also in institutional capacity building among water providers to re-establish the trust of water users.

In what follows, we begin with a review of the literature on water scarcity, risk perception, and bottled water. We then present our methods and the Latin American case studies. The results section presents the most relevant findings from both cases. We conclude with a discussion about the importance of investing in not only infrastructure, but also in reliable and trustworthy governance institutions.

\section{Literature review}

\subsection{Water scarcity: challenging an evident concept}

Concerns about global water availability and its impacts have been expressed during the last decades under the alarming terms of "global water crisis" [8], global "water scarcity" [64], or even "water wars" [55], when referring to the struggles around the allocation of this resource. The majority of related studies are usually limited to volumetric accountings of water reserves with the use of physical indicators that measure water availability or water scarcity [51]. Falkenmark's popular indicator is based on a calculation of the per capita water demand as a fraction of the total water available for human use $[19,20]$. From this perspective, a lack of water is what causes water scarcity and engineering and infrastructural projects that augment water supplies have historically been prescribed as the solution for overcoming water scarcity. However, these quantitative representations of water availability are simplistic and fail to analyze the socio-political causes and implications of water scarcity [43]. Moreover, such approaches tend to present water scarcity as a solely natural phenomenon, obscuring its complexity and “...its linkage to ecological, socio-political, temporal and anthropogenic dimensions" [42]. In this sense, there is a general acknowledgement of the distinction between water shortages - referring to a physical deficit of water - and socially constructed water scarcity as a result of changing lifestyles, growing population and economic sectors fighting over limited water resources [43].

\footnotetext{
1 These findings are not generalizable to other communities that use desalinated water to augment drinking water supplies. Additional research is needed to assess consumer preferences in a variety of institutional and geographical settings.
}

Various frameworks have been developed to classify different types of water scarcity. For example, Wolfe and Brooks [65]) describe a threepart classification system based on drivers of and responses to water scarcity. According to this classification system, first order scarcity is caused primarily by low levels of precipitation and water availability; solutions focus on supply-side engineering solutions such as dams, wells, and desalination. Second order scarcity is a result of inadequate infrastructure and/or poor management; responses focus on demandside water management tools to ensure the efficient use of water. Third order responses are caused by deeply entrenched cultural and institutional norms that have produced our current patterns of water use and shape the way we value water; responses require a radical reassessment of social values, lifestyles, and water user patterns.

Mehta [44]) introduces a "human development approach" to water scarcity classification, which emphasizes the political nature of water scarcity and highlights access and control over water resources as key determinants of water scarcity. She argues that, "scarcity is not 'natural' but generated through socio-political processes, through exclusion, biases, and discrimination." (p. 61). Therefore, this approach analyzes how social and political institutions, cultural norms, and property rights shape individual's access to water, giving special attention to how social variables such as race, class, and gender affect resource access. ${ }^{2}$

Robbins et al. [52]) provide a three-part classification of water scarcity. According to this framework, "hydrological scarcity" results from a combination of climate, affluence, and human population (e.g., in oilrich Gulf States). “Techno-economic scarcity” results from conditions of underdevelopment and a lack of financial investments in infrastructure and technology meet growing water demands. This type of scarcity is particularly acute in rapidly urbanizing cities where water distribution systems are not able to keep pace with urban sprawl. While these first two categories are similar to Wolfe and Brooks [65]) first and second order scarcity, Robbins et al. introduce a unique third driver of scarcity, which they call "perceptual scarcity." This refers to contexts where water treatment is widespread, but there is perception that bottled water is safer (pg. 269).

\subsection{Trust matters: the production of perceptual scarcity and bottled water consumption}

To better understand perceptual scarcity, we draw on risk perception research, which shows that trust is an important factor that shapes the public's acceptance or rejection of new technologies. Risk perception research has roots in the fields of geography, psychology, anthropology, and sociology. One of the aims of this research is to understand how people gauge the severity of different natural hazards and technological risks (e.g., drought, floods, nuclear power, or genetically modified foods). A key question within the field is: why do experts and lay people (i.e. the public) often have different perceptions of risk? (see reviews by $[56,58]$ ).

Early risk perception theories assumed that the public tended to over- or underestimate the degree of risk due to ignorance. Researchers assumed that by developing educational material and informing the public about a controversial risk management issue, the publics' opinion would align with expert judgment [58]. This approach has been criticized for ignoring the psychological, social, and cultural factors that shape people's perceptions of risk $[16,17,56,59]$. Several studies have shown that trust is an important social value that shapes risk perception $[48,49,59]$. Slovic [59]) argues that risk management has become increasingly "contentious" and "polarized" due to an erosion of trust in the "individuals, industries and institutions responsible for risk management" (p. 675). He argues that trust is "asymmetrical" meaning that it is easy to destroy and hard to rebuild:

\footnotetext{
2 The history of water infrastructure development is rife with examples of supply-side engineering solutions (e.g., dams, canals, and irrigation infrastructure) that failed to meet the needs of the poorest and most marginalized citizens (see for example [50,66], or [67])
} 
Trust is fragile. It is typically created rather slowly, but it can be destroyed in an instant - by a single mishap or mistake. This, once trust is lost, it may take a long time to rebuild it to is former state. In some cases, lost trust may never be regained (p. 677).

Slovic's assertions about trust, expert errors, and risk perceptions are supported in recent studies on bottled water consumption [15]. For example, Anadu and Harding [3]) compared the levels of risk perception of tap water and bottled water consumption in communities that have experienced water safety violations. They found that residents of the two communities with past water quality issues drank bottled water more regularly than did residents in the control communities. Furthermore, residents who perceived the highest level of risk associated with tap water lived in the town that had experienced water quality issues over the longest period of time. In a study on the use of water filters and bottled water in Georgia, USA, Abrahams et al. [1]) found that prior problems with tap water was an important factor for respondents who use water filters. The study also found that race was an important determinant of bottled water consumption, with non-whites consuming more bottled water than whites. A study by Hobson et al. [26]) also found race to be an important factor in bottled water consumption. In a survey of parents at a public health center in Salt Lake City, UT, Hobson et al. [26]) found that $58 \%$ of Latino adults and $76 \%$ of Latino children never drink tap water because they fear it causes illness (p. 459). More than half the respondents in Hobson et al.'s survey had been born in Mexico. Crispell and Hedden [12]) report that Spanishspeaking women are the largest consumers of bottled water. They note that Sparkletts, the leading water market vendor at the time, "targeted Hispanics [in the U.S. West] because most Mexican immigrants to the United States have experience with water problems and are accustomed to using alternative sources." (p. 47). Feldman [21]) reports that $82 \%$ of Latinos in southern California drink bottled water (compared to $68 \%$ of whites). Despite the expense of bottled water he argues that it is "attractive to the less affluent who distrust, and often have little confidence in, the institutions that manage tap water" (p. 115). He argues that minority groups are targeted by the bottled water and water filtration industries because these groups have often had past experiences with unreliable water supply in their native countries, which has eroded their trust in tap water:

...[Disreputable companies] seek to take advantage of vulnerable groups who have had bad experiences with pubic water supplies in their native countries. Despite widely accepted claims for tap water safety, such experiences only heighten anxiety and suspicion among those who have vivid memories of what it is like to live in fear of the hazards of tap water, and who have good reason not to trust assurances offered by public officials. (p. 114)

\subsection{Willingness to drink: Public acceptance of desalination}

Numerous studies have been conducted comparing consumer preferences for bottled water versus tap water. Since the 1970s, there have also been studies comparing public acceptance of and willingness to drink recycled wastewater $([4,48,54,62])$. Most of these studies conclude that the public is willing to use recycled water for some uses (e.g., watering the garden), but not more direct uses, such as drinking or bathing children [13]. Ormerod and Scott [48]) examine the relationship between trust in the institutions responsible for municipal water management and the public's willingness to drink recycled wastewater in Tucson, Arizona. They found that the public's acceptance of recycled wastewater for potable purposes is "contingent on trust in the authorities who influence design of sociotechnical systems for water supply and reuse - including water and wastewater utilities, regulators, consultants, academics, and elected local officials" (p. 351).
Most relevant to our research are the limited number of studies that focus on perceptions and preferences of drinking desalinated water. Dolincar and Schäfer [14]) compared hypothetical preferences for recycled and desalinated water in Australia and found that, for drinking purposes, respondents would prefer desalinated water, with $79 \%$ of respondents perceiving desalinated water as drinkable and $50 \%$ perceiving recycled water as drinkable (p. 893). However, both tap water and bottled water were evaluated more favorably for drinking than either desalinated or recycled water. Interestingly, more than two-thirds of respondents indicated that they trusted the providers for both recycled and desalinated water. In southern California, McGuire et al. [41]) compared consumer preferences for desalinated water versus imported water (i.e., from state water projects or the Colorado River). They found that participants could detect differences in imported and desalinated water and preferred imported water, with $62 \%$ of participants indicating that the difference between imported water and desalinated water was objectionable. This study notes that while chlorine levels were considerably higher in desalinated water $(160 \mathrm{mg} / \mathrm{L})$ than in Colorado River water $(91 \mathrm{mg} / \mathrm{L})$, participants did not generally complain about the odor. In Texas, where reverse osmosis technology is increasingly being used in oil fields, Theodori et al. [63]) conducted a survey to assess respondents' views on the level of safety of using desalinated water from oil and gas operations for a variety of uses. Most respondents believed that the safest use for desalinated water was for re-use in the oil and gas industry (94\%) or for other industrial uses (92\%). Other uses for desalinated from oil and gas operations that were considered safe by most respondents include outdoor municipal use (75\%), home irrigation (70\%), and farm or rangeland irrigation (65\%). Less than half $(47 \%)$ of the respondents considered it to be safe to use for instream flows and/or reservoir levels. While $44 \%$ considered desalinated water from oil and gas operations to be safe enough for livestock, only $21 \%$ believed it could be safely used as potable water for human consumption. Our study contributes to this emerging literature by presenting the results of household surveys on preferences for desalinated tap water versus bottled water and linking this preference to past experiences with poor water quality and a long-standing mistrust of water providers and government services in the case study regions.

\section{Case study descriptions and methodology}

This research used a comparative case study approach. As a social science method, case studies provide a detailed examination of a particular event in a particular setting in order to better understand the phenomenon of interest [5]. Case studies typically yield "extremely rich, detailed, and in-depth information" (p. 283). The case study approach is useful for capturing nuances and complex interactions; however, it is not used to produce generalizable results. The use of comparative case studies is "considered more compelling, and the overall study is therefore regarded as more robust" ([70], p. 46). This paper reports the results of household surveys that were conducted in each of the case study locations. Details regarding the survey methods used in each case study are described below. In both cases, raw data from the surveys was entered in Excel worksheets for comparative analysis.

The case studies analyzed here consist of two Latin American urban centers, namely Los Cabos in Mexico, and Antofagasta in northern Chile (Fig. 1). Although these cities have different economies, population sizes and management structures for their desalination plants, (i.e., a public-private partnership in Los Cabos and private ownership in the Antofagasta case), they share a range of characteristics that make them comparable. Both cities are situated in arid areas with intense water-consuming economic activities that result in increasing urban population and consequent water demands (i.e., tourism in Los Cabos and copper mining in Antofagasta). Desalinated seawater is provided for drinking purposes to working class residents in low-income parts of each city. The full cost of desalinated water is not incorporated into residents' water bills in either case, albeit for different reasons. Despite 


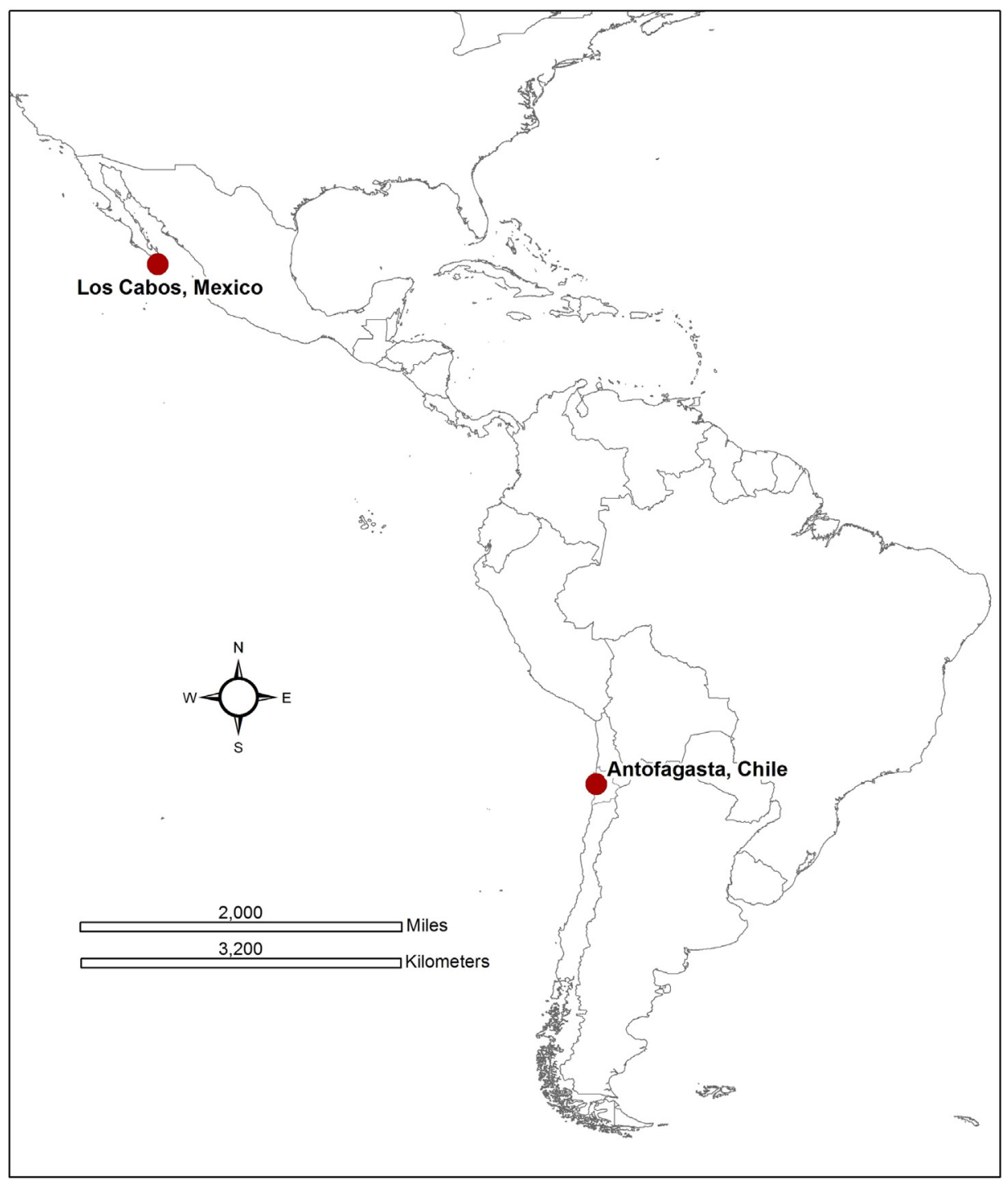

Fig. 1. Location of the two Latin American case studies: Los Cabos, Mexico and Antofagasta, Chile.

having different production capacities (200 lps in Los Cabos and $600 \mathrm{lps}$ in Antofagasta), both desalination plants are large-scale, use state-ofthe-art reverse osmosis technology and both were built in the early 2000s by INIMA - a Spanish water company. In both cities, household surveys were conducted between 2012 and 2014 in neighborhoods served by the desalination plants. The goal of the survey was to assess household water use and consumption practices and perceptions of desalinated water.

\subsection{Los Cabos, Mexico}

Los Cabos is located at the tip of the arid Baja Peninsula, and includes the city of San Jose del Cabo, the city of Cabo San Lucas, and the 18-mile tourist corridor that stretches between the two urban centers (Fig. 1). With vast white beaches and over 300 days of sunshine per year, Los Cabos attracts over a million visitors each year [25]. It is also home to 251,871 residents, most of who are employed in the service sector [28]. Growth in Los Cabos exploded in the 1990s. The number of hotels rooms grew from 1524 in 1982 to 9663 in 1998 and 21,857 new jobs were created between 1988 and 1998 [7]. The growth in the tourist economy attracted migrants from Guerrero, Sinaloa, and other parts of Mexico. The population of the Municipio of Los Cabos (equivalent to a U.S. county) grew from 19,117 in 1980 to 71,031 in 1995, nearly quadrupling in just fifteen years [7]. However, the city's infrastructure did not keep pace with population growth. In 2004, the municipio's water supply network reached only $74 \%$ of the households, leaving $26 \%$ of the residents to rely on pipas (or water trucks) for water provision [27]. ${ }^{3}$ The Los Cabos desalination plant began operation in 2006, producing 2001 of water per second (lps). Since the construction of the new desalination plant, water supply coverage has increased to $96 \%$. However, for $44 \%$ of the water users in Cabo San Lucas, this service is intermittent [27].

While the plant was designed to meet the needs of 40,000 residents in various neighborhoods of Cabo San Lucas, half of the produced water ( $100 \mathrm{lps}$ ) is pumped to the nearby neighborhood of Los Cangrejos with a population of nearly 11,000 residents. This neighborhood is a colonia popular, which refers to the lower socio-economic status of the majority of the residents (equivalent to a lower-income neighborhood, or working-class neighborhood, in the United States). Los Cangrejos was one of the first colonias populares to be established on the outskirts of the Cabo San Lucas city center in the 2000s. Los Cangrejos grew from 3451 residents in 2005 to 10,948 in 2010 [28]. Los Cangrejos is located near the

\footnotetext{
${ }^{3}$ As discussed below, most residents (whether they are connected to the public wate supply or not) purchase purified water that is sold in a refillable 5-gallon garrafón (or plastic jug) for potable purposes due to concerns about water quality.
} 
desalination plant and is the only colonia popular that has a nearly continuous supply of water. A survey of 155 households was conducted in this neighborhood in the spring of 2012. A cluster sampling technique was used to select households [47]. For the purposes of this study, a cluster was defined as neighborhood block. A map from the National Institute of Statistics and Geography [28] showed that there were 155 blocks in the colonia. Using this map as a reference, a survey was conducted with one household on each block. This approach helped to ensure that surveys were distributed over the geographic extent of the colonia and thus account for any variation in water supply on a particular street or block. The survey consisted of closed and open-ended questions to assess household water supply, vulnerability to water scarcity, and perceptions of desalination as a new water supply strategy (see [38] for a full description of the case study and methods).

\subsection{Antofagasta, Chile}

The coastal city of Antofagasta is the capital of the homonymous Region in northern Chile, host to the word's driest desert, Atacama. The city has a population of more than 350,000 residents and a considerable itinerant population associated to the mining activities in the Region. The Antofagasta Region is the most important Chilean region in terms of copper production [32], and host to the world's largest open-pit copper mine, Chuquicamata. The mining boom that took place in the $1990^{\prime}$ $\mathrm{s}$, after the insertion of important international capital, and the uncontrolled urban expansion, as a direct result of the Region's economic development, has brought the Region of Antofagasta to a state of water scarcity [24].

These extractive industries are a major water user in the upper watershed, above the coastal city of Antofagasta. In view of that, seawater desalination is a central strategy in the efforts to complement freshwater resources in the Region, where open-pit mines, industrial agriculture, indigenous communities and urban centers are fighting over the control of the remains of dried up rivers and depleting underground aquifers ([10]; Molina [45]). Although desalinated water is mainly produced to serve the needs of the mining industry, its use in urban areas is gradually gaining more relevance; Antofagasta has been the first city to receive desalinated potable water, ever since a desalination plant located in the La Chimba district started functioning in 2003. The plant started producing $150 \mathrm{lps}$, but has now reached a production capacity of $600 \mathrm{lps}$, enough for supplying an estimated $70 \%$ of households with desalinated water. The construction of a second plant, with a capacity of 1000 lps, started in February 2013, with the aim to make Antofagasta the first urban center in Latin America, and one of the 10 cities worldwide, to be supplied with $100 \%$ desalinated water.

The La Chimba desalination plant has been associated with positive impacts on urban development, as it expedited connectivity to the water distribution network and added value to the area where it is situated [36]. As a result, Antofagasta has experienced its highest historical growth rate since the plant's operation, with annual urban expansion reaching 77 ha in the period between 2006 and the present [9]. At the same time, the La Chimba plant is supposed to have alleviated water scarcity, improved water service discontinuity and solved chronic problems of water quality, related to the natural presence of arsenic (As) ${ }^{4}$ in freshwater, the main source of public water provision for the city of Antofagasta until the plant's construction [36]. Even so, the plant has presented a series of drawbacks that include incidents of service discontinuity due to algae contamination, in 2011, and claims of poor water quality from local civil societies and non-governmental organizations. Added to that, Antofagasta presents the highest water tariffs in the country, with its residents paying $\$ 1255$ Chilean $/ \mathrm{m}^{3}\left(\$ 1.78 \mathrm{USD} / \mathrm{m}^{3}\right)$.

\footnotetext{
4 Given the high concentration of heavy metals in the Region of Antofagasta, up to the 1970 's, when the first abatement plant was installed, the potable water provided to the city had high concentrations of As, exceeding by far the World Health Organization's water quality standards.
}

This price is not only 320\% higher than the equivalent price of water in Santiago, but is also extremely high compared to other northern cities or even to urbanizations in the same Region (e.g., $60 \%$ higher than in Calama) [57].

During June 2014, 100 household surveys were conducted in the neighborhood of La Chimba, the only area in the city that is supplied exclusively with desalinated water, with a population of approximately 29,000 residents. We selected a representative study area of 112 blocks, based on a study conducted by the Chilean Ministry of Housing [23], where we applied a stratified sample [47] that included upper, middle and lower income households. Given the high degree of social segregation in the city of Antofagasta, and the recent growth of households with higher socioeconomic status in the upcoming area of La Chimba, the use of stratified sample was necessary for ensuring that perceptions from households with different socio-economic backgrounds were captured. The survey aimed at discovering differences in water use and consumption practices, before and after the installation of the desalination plant. Surveys consisted of both closed and open-ended questions to assess average household water consumption and main domestic uses for tap water, conformity with water quality standards and service continuity, and the strategies used to face quality concerns and discontinuity issues.

\section{Results}

The results from the surveys conducted in both case study locations present a common paradox. On the one hand, respondents in both cases report being generally satisfied with the desalination plants. However, most respondents do not drink the desalinated tap water that is delivered to their homes.

\subsection{Los Cabos, Mexico}

In the Mexico case study, most survey respondents (76\%) were satisfied with their water service. Since the construction of the desalination plant, their particular neighborhood is connected to the municipal water supply network and has water "dia y noche" ("day and night"). ${ }^{5}$ Furthermore, respondents reported paying less to meet their households' monthly water needs. Prior to the construction of the desalination plant, respondents generally paid $\$ 400-1000$ pesos/month (US\$33-US\$85/month) to have water delivered to their houses by private water trucks, or pipas. Now that they are connected to the public water supply network, most respondents pay \$50-299 pesos/month (US\$4-\$25/month) for their municipal water bill. These are clear benefits.

However, when asked what they use the desalinated tap water for, only $13 \%$ of respondents reported using it for drinking water. Instead, most respondents continue to buy agua purificada (purified water) in 5-gallon garrafones. Respondents reported spending nearly as much on bottled water each month as they now spend on their monthly city water bill. In other words, residents essentially pay two water bills each month. When it comes to washing fruit and vegetables, $89 \%$ of respondents reported using desalinated tap water, but $11 \%$ preferred to use bottled water for these purposes. However, all respondents $(n=$ 155 ) were comfortable using desalinated tap water for bathing, cleaning the house, and washing dishes.

Despite the relatively new distribution network and the water utility's assurance that the water delivered from the desalination plant is potable, respondents' primary reason for not drinking the desalinated tap water was concern that the water is not hygienic or could cause

\footnotetext{
${ }^{5}$ Increased access to water did not occur throughout the city. The survey was conducted in the neighborhood located nearest the desalination plant and receives half of the water produced by the desalination plant. Desalinated water was not distributed to all neighborhoods across the city (see [40]).
} 
illness ( 66 of 115 comments). ${ }^{6}$ Other reasons that respondents gave for not drinking the desalinated tap water included: too much chlorine (30 comments), accustomed to drinking purified water ("garrafón") (18 comments), general dislike ( 9 comments), uncertainty of what's in the water (6 comments), poor taste/salty (6 comments), source of the water (i.e., seawater) (5 comments). Two respondents commented that they preferred to buy purified water, so that they would not have to boil the tap water. Another explained that they buy purified water because there are children in the house. One person noted that the tap water "can stain your clothes" and someone else had heard that "it isn't recommended" to drink the tap water.

The few respondents who reported drinking the tap water qualified their response. For example, one respondent said he drinks tap water when he doesn't have money to refill a garrafón. Another said he usually buys purified water, but sometimes there is no work, so that's when he drinks tap water, adding that he has a filter to treat the tap water anyway. One respondent said that she boils the tap water to purify it. Only two respondents said that they drink it because it's "purified" or "clean."

\subsection{Antofagasta, Chile}

Results from the Antofagasta case study reveal similar trends. The construction of the desalination plant has guaranteed water service continuity for the whole city, a problem that was quite severe during the 1980s. Desalinated water has also eliminated the possibility of high concentrations of arsenic in tap water, a natural characteristic of regional freshwater sources, associated with high indices of lung and bladder cancer mortality in the city's residents [22,35]. Nevertheless, surveyed household water consumers do not consider that the quality of tap water has changed since the installation of the desalinization plant. Household survey results reveal a paradox: when asked about the organoleptic properties of tap water (i.e., smell, taste, visual appeal) most respondents grade these positively, however when they are asked to evaluate their overall satisfaction with the quality of tap water, only $20 \%$ report being satisfied and $13 \%$ report being indifferent.

In two-thirds of the households (66\%), tap water is not used for drinking by the totality of the household members. When further asked, the respondents declared that the household members that do not consume tap water for drinking are principally children, elderly people and workers from other parts of Chile. All surveyed households use tap water for housecleaning, personal hygiene and cooking. For the latter use, in most households water is boiled before being used.

The explanation behind the rejection of drinking tap water lies in the perception of the surveyed population on tap water's health effects. Nearly three-quarters of respondents $(72 \%)$ believe that tap water could negatively affect their health. Responses are dominated by the belief that tap water is harmful due to the presence of arsenic and that tap water can cause cancer. This fact highlights the importance of past traumatic incidents concerning water quality. It is important to note that, even residents who are aware that they are consuming desalinated seawater, still believe that tap water contains arsenic, which could be harmful for their health. To a lesser extent, the surveyed population rejects tap water due to its taste, the only organoleptic characteristic that has been valued negatively by the totality of respondents.

Residents in the La Chimba, therefore, rely on alternative drinking water sources, mainly 20-liter containers (bidónes) of purified water. Even though it is known that purified water is essentially filtered tap water, residents prefer this to the water provided by the water company. More than $80 \%$ of surveyed households use bottled water; most of them have done so for the last five to ten years i.e., after the desalination plant was installed. According to the survey results, on average, households that are provided with desalinated water consume more than four

\footnotetext{
${ }^{6}$ Respondents could list more than one reason for not drinking desalinated tap water.
}

20-liter containers of purified water and three bottles of 6-liter mineral water per month. This means that households in northern Antofagasta have to add the cost of bottled water, tap filters, and energy spent for boiling tap water for cooking to their water bill, in order to calculate the totality of costs associated to household water consumption.

With regards to the changes in household water use and consumption habits observed after the installation of the desalination plant, only $12 \%$ of the respondents have detected a change, most of whom reported consuming less water. Further questions revealed that this is due to the high prices and low perception of water quality, rather than the consumers' knowledge of desalinated water intake. Additionally, a small percentage the surveyed population who reside in the city before the installation of the plant, and has noted changes in service, declared that the quality of tap water has been improved.

\subsection{Comparison of the case study results}

The desalination plants in the two cities under study both produce potable water. In the case of Los Cabos, Mexico, the desalination plant decreased monthly water expenditures by achieving connection to the distribution network and improving service continuity for the surveyed residents, who previously relied on water trucks (pipas) for household water provision. In the case of Antofagasta, the plant came to substitute part of the city's water provision with freshwater with desalinated water, a transition that was not neither obvious nor perceived by the totality of the consumers.

Even though in both cases consumers principally prefer to drink bottled water, this is due to different reasons; in the Mexican case study residents are accustomed to using bottled water as their regular source

Table 1

Comparison of survey results from desalinated water consumers in Los Cabos, Mexico, and Antofagasta, Chile.

\begin{tabular}{|c|c|c|}
\hline & $\begin{array}{l}\text { Residents of Los } \\
\text { Cangrejos, } \\
\text { Los Cabos, Mexico }\end{array}$ & $\begin{array}{l}\text { Residents of La Chimba, } \\
\text { Antofagasta, Chile }\end{array}$ \\
\hline $\begin{array}{l}\text { Percent of residents who } \\
\text { report being satisfied or } \\
\text { indifferent with the quality } \\
\text { of the water }\end{array}$ & $76 \%$ & $33 \%$ \\
\hline $\begin{array}{l}\text { Percent of residents who } \\
\text { drink desalinated tap } \\
\text { water }\end{array}$ & $13 \%$ & $34 \%$ \\
\hline $\begin{array}{l}\text { Primary concerns about } \\
\text { desalinated tap water }\end{array}$ & $\begin{array}{l}\text { 1. Not hygienic or } \\
\text { could cause } \\
\text { illness } \\
\text { 2. Too much } \\
\text { chlorine } \\
\text { 3. Accustomed to } \\
\text { drinking puri- } \\
\text { fied water } \\
\text { ("garrafón") } \\
\text { 4. General dislike } \\
\text { 5. Uncertainty of } \\
\text { what's in the } \\
\text { water } \\
\text { 6. Poor taste/salty } \\
\text { 7. Source of the } \\
\text { water (i.e., } \\
\text { seawater) }\end{array}$ & $\begin{array}{l}\text { 1. Believe that tap water } \\
\text { could negatively affect } \\
\text { their health due to the } \\
\text { presence of arsenic } \\
\text { 2. Tap water can cause } \\
\text { cancer } \\
\text { 3. Poor taste }\end{array}$ \\
\hline $\begin{array}{l}\text { Consumption of bottled } \\
\text { water }\end{array}$ & $\begin{array}{l}87 \% \text { buy bottled } \\
\text { water and/or boil } \\
\text { water }\end{array}$ & $\begin{array}{l}80 \% \text { buy bottled water } \\
37 \% \text { use tap filters }\end{array}$ \\
\hline $\begin{array}{l}\text { Changes in service and habits } \\
\text { after the plant's installation }\end{array}$ & $\begin{array}{l}\text {-Cheaper water for } \\
\text { household uses } \\
\text {-Connection to the } \\
\text { distribution } \\
\text { network } \\
\text {-Improved } \\
\text { continuity of } \\
\text { service }\end{array}$ & $\begin{array}{l}\text {-Better tap water quality } \\
\text {-Augmentation of bottled } \\
\text { water consumption } \\
\text {-Decreased tap water } \\
\text { consumption }\end{array}$ \\
\hline
\end{tabular}


of water, and have had difficulties in changing to tap water, although they consider it of good quality for other uses. In the Chilean case study, consumers have had traumatic past experiences with the quality of tap water, thus causing them to fear it, even when they know that it is desalinated. In both cases, the surveyed population avoids drinking tap water without previous treatment (such as boiling or use of tap filters), mainly because of health concerns. A comparative summary of the findings is given in Table 1.

\section{Discussion and conclusions}

Based on the above results, we argue that in both cities the supply of desalinated water for household uses highlights a different type of scarcity - perceptual scarcity. Slovic's [59]) assertions on the strong link between trust and risk perception are particularly useful in our case studies as we explain why, despite assurance from experts that desalinated water is safe and potable, most survey respondents spend a considerable portion of their monthly budget on bottled water, rather than drink the desalinated water delivered to their tap. We argue that traumatic past experiences with poor water quality and long-standing mistrust of local water utilities and government services shape respondents' perception of desalinated tap water. Recent studies on bottled water also support the assertion that preferences for bottled water are shaped by these two factors $[12,21,26]$.

However, it is important to note that there are other factors that may influence preferences for bottled water. First, marketing efforts by bottled water companies may encourage greater bottled water consumption [21,52]. Seconds even if desalinated water is potable at the point of production (i.e., in the desalination facility), its quality can be altered between the point of production and point of consumption [31]. Deteriorating municipal and household pipes are susceptible to contamination, which affects water quality. Furthermore, the intermittent nature of many supply systems in developing countries, (such as the tandeo system used in many parts of Mexico) can cause microbial growth and water-borne diseases $[2,18,30]$. Third, many consumers in both case studies complained of excessive chlorine taste, attributed to the water treatment process.

While these factors are important, we argue that is also important to understand the deeply rooted attitudes and beliefs toward tap water and government services that may lead to consumers' rejection of desalinated tap water as a source of potable water. Specifically, as seen in the case studies presented here, Latinos' mistrust of their water utilities companies along with past traumatic experiences work to produce perceptual water scarcity $[12,21,26,59]$. The case of Antofagasta is emblematic of this, where even residents who are aware that they consume desalinated water, still believe that it has high concentrations of Arsenic, which can negatively affect their health. The high occurrence of lung and bladder cancer and the white stains on older people's skin, both associated to long-term tap water intake and use respectively, are still a vivid part of the "ghost of Arsenic" (el fantasma de Arsenico) that dominates people's perception of the city's potable water.

It is important to emphasize that the focus of our research is on public perception of desalinated tap water and consumer preferences for desalinated tap water versus bottled water, and not on the comparison between the qualities of desalinated and bottled water. As noted above, there are many factors that may affect public perception of water quality and consumer preference for bottled water. Additionally, in many cases, the quality of desalinated water is altered when it reaches consumers because of deteriorated distribution networks; meanwhile the bottled water that is purchased by many respondents in our case studies is typically desalinated tap water that has undergone an additional membrane treatment at a neighborhood purificadora (water purifying station) prior to being bottled.

In sum, while the addition of desalinated water in the urban municipal water supply system may overcome physical and techno-economic scarcities, it may not adequately address perceptual scarcities. Consequently, our conclusions indicate that the solution to overcome perceptual scarcity is not merely an educational campaign designed to convince residents that desalinated is safe. Rather, a more fundamental change is needed. More attention has to be given to improving water management agencies and institutions, whether public or private. The findings highlight the importance of investing not only in new infrastructure such as desalination, but also maintaining existing infrastructure (e.g., water delivery systems) and investing in institutional capacity to build reliability and trust within water management agencies.

\section{Acknowledgements}

The research in Chile was funded by the Chilean National Commission for Scientific and Technological Research (CONICYT), in the context of the Fondecyt Iniciación project 11130631. The research in Mexico was funded by a National Science Foundation Doctoral Dissertation Research Improvement grant and a Fulbright-García Robles award.

\section{References}

[1] N.A. Abrahams, B.J. Hubbell, J.L. Jordan, Joint production and averting expenditure measures of willingness to pay: do water expenditures really measure avoidance cost? Am. J. Agric. Econ. 82 (2) (2000) 427-437.

[2] S.S. Abu Amr, M.M. Yassin, "microbial contamination of the drinking water system and its impact on human health in khan Yunis governorate, Gaza strip: seven years of monitoring (2000-2006), Public Health 122 (11) (2008) $1275-1283$

[3] E. Anadu, A. Harding, Risk perception and bottled water use, J. AWWA 92 (11) (2000) 82-92.

[4] S. Baggett, P. Jeffrey, B. Jefferson, Risk perception in participatory planning for water reuse, Desalination 187 (2006) 149-158.

[5] B.L. Berg, Qualitiative Research Methods for the Social Sciences, sixth ed. Pearson, Boston, MA, 2007.

[7] J.L. Borja Santibáñex, G.R. Cruz Chávez, J. Juárez Mancilla, I. Rodríguez Villalobos, Políticas de descentralización Y Gobierno Local: El Desarrollo turístico de Los Cabos, Baja California Sur, Cuadernos Universitarios, La Paz, México, 2006.

[8] N.L. Cain, P.H. Gleick, Real numbers: the global water crisis, Issues Sci. Technol. 21 (2005) 79-81.

[9] CEPAL (2013) Sendas bajas en carbono para el desarrollo de ciudades sostenibles en América Latina y el Caribe. Propuesta de recuperación urbana para la promoción de ciudades sostenibles, el caso de la ciudad de Antofagasta. Unpublished report. Comisión Económica para América Latina y el Caribe: Santiago, Chile

[10] Chile Sustentable, Conflictos Por El Agua en Chile: Urgen Cambios Legales Y Constitucionales en Las Políticas de Agua, Santiago, Chile, Programa Chile Sustentable, 2012.

[11] H. Cooley, P. Gleick, G. Wolff, Desalination, with a Grain of Salt: Perspectives from California, Oakland, CA, USA, Pacific Institute, 2006.

[12] D. Crispell, C.R. Hedden, Water works, Am. Demogr. 18 (1) (1996) 46.

[13] S. Dolnicar, A. Hurlimann, B. Grün, What affects public acceptance of recycled and desalinated water? Water Res. 45 (2011) 933-943.

[14] S. Dolnicar, A.I. Schäfer, Desalinated versus recycled water: public perceptions and profiles of the accepters, J. Environ. Manag. 90 (2009) 888-900.

[15] M.F. Doria, Bottled water vs. tap water: understanding consumers' preferences, J. Water Health 4 (2) (2006) 271-276.

[16] M. Douglas, Essays in Cultural Theory, Routledge, London, New York, 1992

[17] M. Douglas, A. Wildavsky, Risk and Culture: An Essay on the Selection of Technological and Environmental Dangers, University of California Press, Berkley and Los Angeles, California, USA, 1982.

[18] A. Ercumen, B.F. Arnold, E. Kumpel, Z. Burt, I. Ray, K. Nelson, et al., Upgrading a piped water supply from intermittent to continuous delivery and association with waterborne illness: a matched cohort study in urban India, PLoS Med. 12 (10) (2015), e1001892, http://dx.doi.org/10.1371/journal.pmed.1001892.

[19] M. Falkenmark, J. Lundqvist, C. Widstrand, Macro-scale water scarcity requires microscale approaches: aspects of vulnerability in semi-arid development, Nat. Res. Forum 13 (4) (1989) 258-267.

[20] M. Falkenmark, C. Widstrand, Population and water resources: a delicate balance. Population bulletin, population reference bureau, 1992 (Accessed 1/27/16) http:// www.ircwash.org/sites/default/files/276-92PO-10997.pdf.

[21] D.L. Feldman, Water, Polity Press, Cambridge, UK, 2012.

[22] M.I. Fernández, J.F. López, B. Vivaldi, F. Coz, Long-term impact of arsenic in drinking water on bladder cancer health care and mortality rates 20 years after end of exposure, J. Urol. 187 (2012) 856-861, http://dx.doi.org/10.1016/ j.juro.2011.10.157.

[23] O. Figueroa, Análisis de Tendencias de localización, Caso Sistema Urbano Ciudad de Antofagasta, Estudio Realizado Por El Ministerio de Vivienda Y Urbanismo. División de Desarrollo Urbano Gobierno de Chile en Conjunto Con SEREX PUC Consultores, 2007.

[24] Gobierno Regional de Antofagasta, Estrategia Regional de Desarrollo 2009-2020, Santiago, Chile, Gobierno de Chile, 2008. 
[25] H. XI Ayuntamiento de Los Cabos, Plan de desarrollo municipal 2011-2015, Ayuntamiento de Los Cabos, Los Cabos, BCS: Mexico, 2011.

[26] W.L. Hobson, M.L. Knochel, C.L. Bvington, P.C. Young, C.J. Hoff, K.F. Buchi, Bottled, filtered, and tap water use in Latino and non-Latino children, Arch. Pediatr. Adolesc. Med. 161 (5) (2007) 457-461, http://dx.doi.org/10.1001/archpedi.161.5.457.

[27] IMPLAN (Instituto Municipal de Planeación de Los Cabos), Actualización del Plan Director de Desarrollo Urbano de San José Y Cabo San Lucas, B.C.S. 2040 (Preliminar V03 24/Oct/11), IMPLAN, Los Cabos, BCS, Mexico, 2011.

[28] INEGI (Instituto Nacional de Estadística y Geografía), Censo Nacional, 2010. Sistema Estatal y municipal de base de Datos, http://sc.inegi.org.mx/sistemas/cobdem/2010 (accessed 2 April 2013).

[30] E. Kumpel, K.L. Nelson, Intermittent water supply: prevalence, practice, and microbial water quality, Environ. Sci. Technol. (2016), http://dx.doi.org/10.1021/acs.est. 5 b03973.

[31] Y. Lee, An evaluation of microbial and chemical contamination sources related to the deterioration of tap water quality in the household water supply system, Int. J. Environ. Res. Public Health 10 (2013) 4143-4160.

[32] G. Lagos, E. Blanco, Mining and development in the region of Antofagasta, Res. Policy 35 (2010) 265-275, http://dx.doi.org/10.1016/j.resourpol.2010.07.006

[33] H. March, The politics, geography, and economics of desalination: a critical review, WIREs Water 2015 (2) (2015) 231-243, http://dx.doi.org/10.1002/ wat2.1073.

[34] H. March Corbella, D. Saurí, Crisis-ridden water governance: the Drought of 2008 in Metropolitan Barcelona, Paper Presented at the RGS-IGB Annual Conference, Manchester, UK, 2008.

[35] G. Marshall, C. Ferreccio, Y. Yuan, M.N. Bates, C. Steinmaus, S. Selvin, J. Liaw, A.H. Smith, Fifty-year study of lung and bladder cancer mortality in Chile related to arsenic in drinking water, J. Natl. Cancer Inst. 99 (12) (2007) 920-928, http://dx.doi.org/ 10.1093/jnci/djm004.

[36] F. Martín, J.M. Sánchez, Planta Desaladora de Antofagasta: Un Impacto Positivo Al Medio Ambiente. I Congreso de Ingeniería Civil, Territorio Y Medio Ambiente, Colegio de Ingenieros de Caminos, Canales y Puertos, Madrid, 2002.

[37] R.I. McDonald, P. Green, D. Balk, B.M. Fekete, C. Revenga, M. Todd, M. Montgomery, Urban growth, climate change, and water availability, Proc. Natl. Acad. Sci. U. S. A. 108 (15) (2011) 6312-6317.

[38] J. McEvoy, Desalination and development: the socioecological and technological transformation of the Gulf of California(Doctoral dissertation) ProQuest Dissertations and Theses (Publication Number: 3592757), 2013.

[39] J. McEvoy, Can the adoption of desalination technology lead to aquifer preservation? A case study of a sociotechnical water system in Baja California Sur, Mexico, Water 7 (2015) 5224-5238.

[40] J. McEvoy, M. Wilder, Discourse and desalination: potential impacts of proposed climate change adaptation interventions in the Arizona-Sonora border region, Glob. Environ. Chang. 22 (2012) 353-363.

[41] M.J. McGuire, J. Loveland, E.G. Means, J. Garvey, Use of flavour profile and consumer panels to determine differences between local water supplies and desalinated seawater, Water Sci. Technol. 55 (5) (2007) 275-282.

[42] L. Mehta, Contexts and constructions of water scarcity, Econ. Polit. Wkly. 38 (48) (2003) 5066-5072.

[43] L. Mehta, Whose scarcity? Whose property? The case of water in western India, Land Use Policy 24 (2007) 654-663.
[44] L. Mehta, Water and human development, World Dev. 59 (2014) 59-69.

[45] M. Otarola, El río Loa: Usos Y Conflictos Por El Agua en El Desierto de Atacama, Comunidades indígenas, Mineras, Ciudades Y Pueblos, Lima, Perú, Infoandina, 2006.

[46] National Research Council (NRC), Desalination: A National Perspective, The Nationa Academies Press, Washington, DC, 2008.

[47] W.L. Neuman, Social Research Methods: Qualitiative and Quantiative Approaches, sixth ed. Pearson, Boston, MA, 2006.

[48] K.J. Ormerod, C.A. Scott, "Drinking wastewater: public Trust in Potable Reuse, Sci. Technol. Hum. Values 38 (3) (2012) 351-373.

[49] S. Rayner, Risk perception, technoloy acceptance, and institutional culture: case studies of some new definitions, in: B. Rück (Ed.), Risk Is a Construct: Perceptions of Risk Perception, Knesebeck, Munich 1993, pp. 197-220.

[50] M. Reisner, Cadillac Desert: The American West and its Disappearing Water, Penguin Books, New York, USA, 1986.

[51] F.R. Rijsberman, Water scarcity: fact or fiction? Agric. Water Manag. 80 (1-3) (2006) 5-22

[52] P. Robbins, J. Hintz, S.A. Moore, Bottled Water, in: P. Robbins, J. Hintz, S.A. Moore (Eds.), Environment and Society; a Critical Introduction, Wiley Blackwell, UK 2014, pp. 259-278.

[54] M. Salgot, E. Huertas, S. Weber, W. Dott, J. Hollender, Wastewater reuse and risk: definition of key objectives, Desalination 187 (2006) 29-40.

[55] V. Shiva, Water Wars: Privatization, Pollution, and Profit, South End Press, Cambridge, MA, 2002.

[56] J.F. Short, The social fabric of risk: toward the social transformation of risk analysis Am. Sociol. Rev. 49 (6) (1984) 711-725.

[57] SISS, Tarifas vigentes. Superintendencia de Servicios Sanitarios, 2013 (Available at:) http://www.siss.gob.cl/577/w3-propertyvalue-3512.html (Last accessed: 20 April 2013).

58] P. Slovic, Perception of risk, Science 236 (4799) (1987) 280-285.

[59] P. Slovic, Perceived risk, trust, and democracy, Risk Anal. 13 (6) (1993) 675-682.

[60] E. Swyngedouw, Into the sea: desalination as hydro-social fix in Spain, Ann. Assoc Am. Geogr. 103 (2) (2013) 261-270.

[62] S. Toze, Water reuse and health risks-real vs. perceived, Desalination 187 (2006) s41page $>-s 51$.

[63] G.L. Theodori, B.J. Wynveen, W.E. Fox, D.B. Burnett, Public perception of desalinated water from oil and gas field operations: data from Texas, Soc. Nat. Res. Int. J. 22 (7) (2009) 674-685, http://dx.doi.org/10.1080/08941920802039804.

[64] United Nations, Water scarcity. United Nations, 2013 (Available at:) http://www.un. org/waterforlifedecade/scarcity.shtml (Last accessed: 29 April 2013).

[65] S. Wolfe, D.B. Brooks, Water scarcity: an alternative view and its implications for policy and capacity building, Nat. Res. Forum 27 (2003) 99-107.

[66] J. Worster, Rivers of Empire: Water, Aridity and the Growth of the American West, Oxford University Press, Oxford, UK, 1985.

[67] World Commission on Dams, Dams and development: a new framework for decision-making, 2000 (Retrieved from) http://www.dams.org/publications/publication3.htm.

[68] World Water Council, A Water Secure World: Vision for Water, Life and the Environment, Marseille, France, World Water Council, 2000.

[70] R.K. Yin, Case Study Research, third ed. Sage, Thousand Oaks, CA, 2003. 